also Krassovsky et al., 1973). Groups of similar signals are discernible on the background of chaotic fluctuations. The speed of the propagation of signals and the direction into which they move can be determined from the delay of their appearance to different spectrograph slit sections. Sometimes similar signals are observed only in two directions or there is a strong signal only on one direction out of three. This may be due to the shorter extent of the inhomogeneities as compared with the base of obscrvations or due to the passage of only the border of extended inhomogeneities through the edge of the region observed. Sometimes along all directions there are only temperature fluctuations which do not coincide in shape. However, they may be due to the superposition of the waves propagated from different directions.

The shortest pulses shown in Fig. 1 so far have not been identified in different azimuths. Their duration is close to the short-period limit of internal gravity waves or to the long-period limit of acoustic waves. All this, as has already been pointed out (Davies et al., 1973) may be associated with the Doppler effect due to fast circulation of the atmosphere in the region of the origin of hydroxyl emission. If pulses existing only in one of the azimuths result from the motion of the sections of the atmosphere with inhomogeneous emission of hydroxyl due to vertical eddies, one has to assume that these inhomogeneities either appear very quickly and are also destroyed, without having time to reach another section observed, or exist for a longer time, but move very slowly and cannot reach another section observed during the observation time. The latter is possible also in the case of internal gravity waves with periods close to their short-period limit.

At present sufficient data have not been accumulated to systematize the amplitudes, directions and speeds of the motion of the inhomogeneities of rotational temperature. Nevertheless, the amplitude of the deviations of the hydroxyl rotational temperature from its average values is in good correlation with local geomagnetic $K$-indices preceding these deviations by $3 \mathrm{hr}$. So far we have succeeded in observing the speeds from several tens to several hundreds of $\mathrm{m} / \mathrm{sec}$ in diverse directions from cyclones. All this undoubtedly points to a non-uniform structure of hydroxyl emission in time and space and testifies to the similarity of the behaviour of minor active constituents of the upper atmosphere due to which hydroxyl emission appears.

Institute of Physics of the Atmosphere, V. I. KrassovsKY U.S.S.R. Academy of Sciences, Moscow, M. V. Shaghev U.S.S.R.

\title{
REFERENCES
}

Davies, K., Jonks, T. B. and Weaver, P. F. (1973). Planet. Space Sci. 21, 147.

Fedorova, N. I. (1967). Aurorae and airglow. U.S.S.R. Acad. Sci. Moscow 13, 22.

Krassovsky, V. I. (1957). Mém. Soc. Roy. Sci. Llege, Quartieme Série 18, 58.

KrassovsKY, V. I. (1971), J. atmos. terr. Phys. 33, 1499.

KrassovSKY, V. I. (1972). Annls Géophys. 28, 739.

KRAssovsky, V.I. and ShaGaEV, M. V. (1974). J. atmos. terr. Phys. 36, 373.

SHAGAEV, M. V. (1974). J. atmos. terr. Phys. 36. In press.

Sherov, N. N. (1974), Geomagn. Aeron 14, In press.

Shcheglov, P. V. (1963). Electronic telescopy. Phys. Math. Press, Moscow.

TAranova, O. G. (1967). Aurorae and airglow. USSR Acad. Sci. Moscow 13, 13.

Planet. Space Sct. 1974, Vol. 22, pp. 1337 to 1340. Pereamon Prese. Printed in Northern Ireland

\section{ON DETERMINING THE OZONE NUMBER DENSITY DISTRIBUTION FROM OAO-2 STELLAR OCCULTATION MEASUREMENTS}

\section{(Received 15 Janwary 1974)}

\begin{abstract}
Stellar occultation data from the $2460 \AA$ and 2980 A channels of the OAO-2 stellar photometers have been used to derive the nighttime ozone number density distribution in the low latitude mesosphere. The nighttime ozone distribution obtained from both channels are similar indicating a maximum in the ozone distribution near $80 \mathrm{~km}$ of $2-3 \times 10^{8} \mathrm{~cm}^{-8}$.
\end{abstract}

\section{INTRODUCTION}

Hays and Roble (1973) and Roble and Hays (1973) bave used the stellar occultation measurements in the $2500 \AA$ region made by the orbiting astronomical observatory satellite $(O A O-2)$ to retrieve the nighttime 
vertical number density distribution of ozone in the low latitude mesosphere. The results from approximately 12 stellar occultations showed a bulge in the nighttime ozone number density with a peak of 1$2 \times 10^{8} \mathrm{~cm}^{-8}$ at approximately $83 \mathrm{~km}$ and a minimum near $75 \mathrm{~km}$. Recently, Rosenberg et al. (1974) have suggested that the stellar u.v. attenuation measured near $80 \mathrm{~km}$ during occultation (Fig. 1) may not be due to ozone absorption but is probably due to extinction caused by atmospheric aerosols. They argue that the aerosol layer in the region where noctilucent clouds are observed around $80 \mathrm{~km}$ can cause an extinction of about 10 per cent which corresponds to the observed values. Therefore, they suggest that the extinction can be explained by the existence of nighttime noctilucent clouds in low latitudes without assuming the existence of an additional ozone layer. They also point out that near the region of about $2400 \AA$ the aerosol scattering cross-section is close to the absorption cross-section but that the scattering crosssection does not vary greatly with wavelength. Thus, it would be possible, through measurements in two regions of the spectrum, to differentiate between absorption and scattering experimentally.

In this paper we present data in two spectral channels that resolve the scattering versus ozone absorption question. The OAO-2 satellite has four stellar photometers each with a number of u.v. filters to make measurements in certain isolated spectral regions. The channels normally used for the stellar occultation measurements are shown in Fig. 1 of Hays and Roble (1973). Almost all of our ozone measurements were

(a)
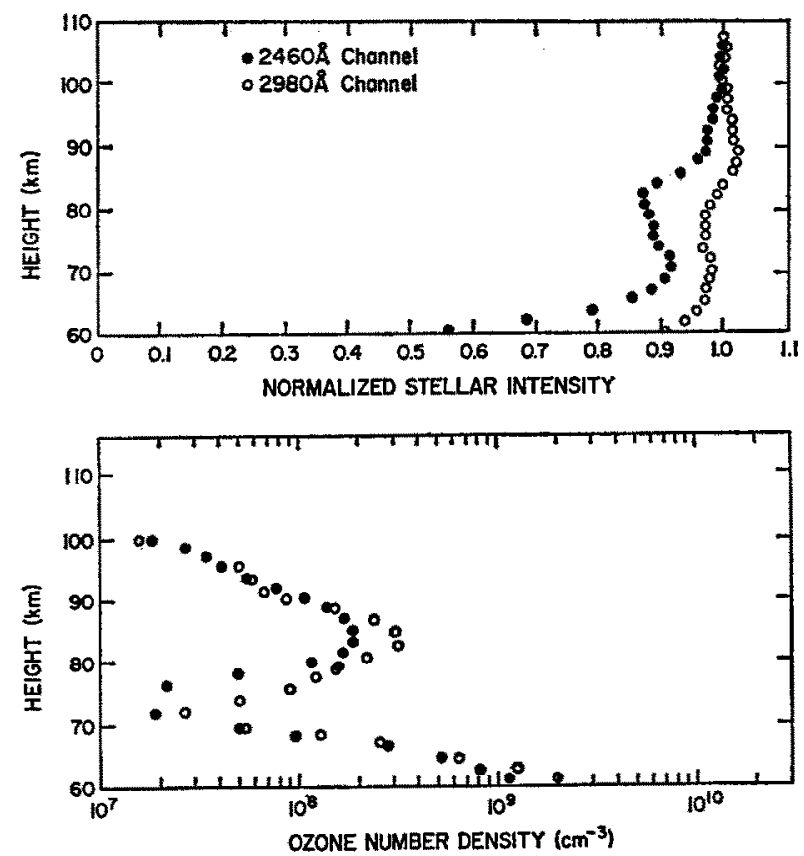

Fig. 1. (a) The measured normarized stellar signal in the $2460 \AA$ channel and $2980 \AA$ CHANNEL. DURING Occultation ON 3 ApRIL 1971 AT 22 HR 33 Min LT at $36^{\circ} \mathrm{N}$ LAT AND $114^{\circ}$ W LONG.

(b) THE RETRIEVED OZONB NUMBER DENSITY DISTRIBUTION FROM THE STELLAR OCCULTATION MEASUREMENTS.

made with the $2390 A$ and $2460 A$ channels in the Hartley Continuum region where the ozone absorption cross-section is a smooth function of wavelength. On occasion measurements were also made with the $2980 \AA$ channel; however, these data were not published because of the difficulties involved in reducing the data in the Huggins Band system of ozone around $3000 \AA$. But data in this channel can be used to resolve the aerosol scattering versus ozone absorption in the $70-90 \mathrm{~km}$ altitude region.

\section{OCCULTATION DATA}

The normalized stellar intensity profile for the 2460 and $2980 \AA$ channels during occultation on orbit 12178 on 3 April 1971 at $22 \mathrm{hr} 33 \mathrm{~min}$ is shown in Fig. 1(a). Above $100 \mathrm{~km}$ the ozone absorption is negligible and both channels have a normalized intensity of 1.0 . In the $2460 \AA$ channel, the stellar signal remains constant until near $90 \mathrm{~km}$ where ozone absorption begins to cause attenuation. The stellar signal decreases to about $80 \mathrm{~km}$ and below that altitude a slight increase in the signal occurs, peaking near $74 \mathrm{~km}$ before 
there is again a rapid decrease in the stellar signal until occultation near $45 \mathrm{~km}$. In the $2980 \AA$ channel there is a slight intensity increase in the signal near $90 \mathrm{~km}$ that is due to the $2972 \AA$ atomic oxygen emission OI $\left({ }^{1} S-{ }^{3} P_{1}\right)$ in the atomic oxygen recombination layer. The emission layer is more commonly observed as the $5577 \AA$ atomic oxygen green line $\mathrm{OI}\left({ }^{1} S-{ }^{1} D\right)$ (Offermann and Drescher, 1973; Donahue et al., 1973). A normalized volume emission profile of the $5577 \AA$ emission line as determined from the rocket measurements of Offermann and Drescher (1973) is shown in Fig. 3(a). The peak of the emission layer occurs near $97 \mathrm{~km}$ and falls off rapidly away from that altitude. Below $85 \mathrm{~km}$, the signal decreases slightly showing a small attenuation near $80 \mathrm{~km}$, and peaks again near $70 \mathrm{~km}$ before the signal decreases again at lower altitudes. The main feature in this figure is that the ozone absorption in the $2460 \mathrm{~A}$ channel near $80 \mathrm{~km}$ is much greater than the absorption in the $2980 \AA$ channel in the same altitude region.

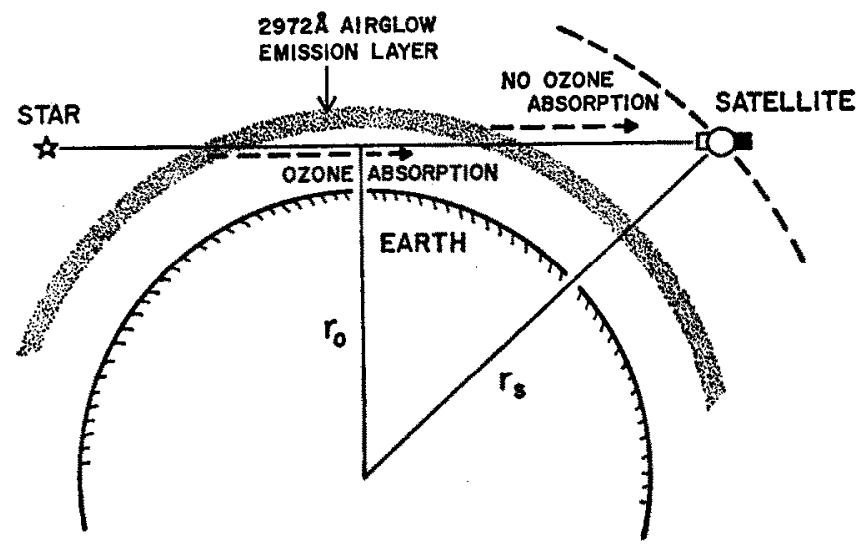

Fig. 2. THE GRometry of OCCULTATION CONSIDERING THE INFLUENCE OF THE 2972 oI $\left({ }^{1} S-{ }^{3} P_{1}\right)$ ATRGLOW EMASSION IN TKE 2980 A CHANNEL.
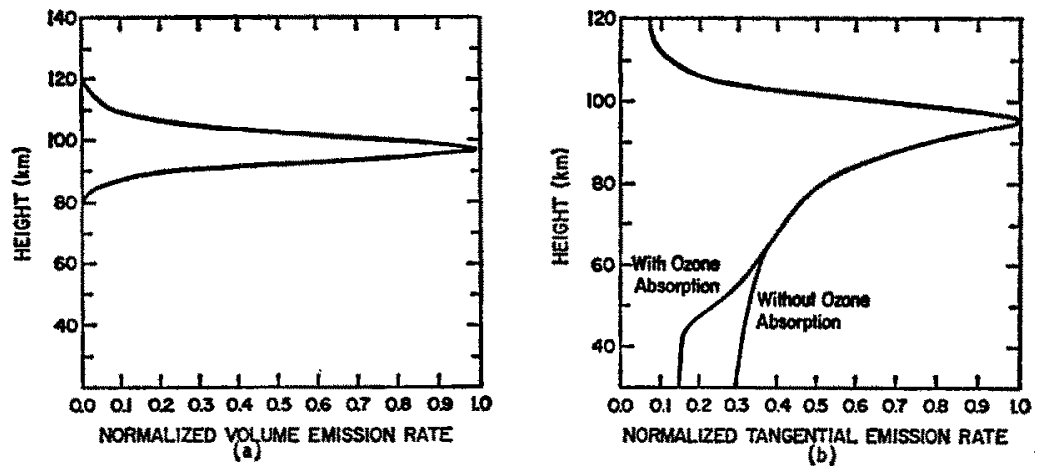

FIG. 3. (a) THE NORMALIZED VOLUME EMISSION RATE PROFILE FOR THE $2972 \AA$ AIRGLOW EMTSSION, ASSUMED SIMILAR TO THE $5577 \AA$ AIRGLOW EMISSION MEASUREMENTS OF OFFERMANN AND DRESCHER (1973).

(b) THB CALCULATED NORMALUZED TANGENTIAL TRANSMisSTON AS ORSERVED BY THE SATELLITE WITH AND WITHOUT THE EFFECT OF OZONE ABSORPTION OF THE EMISSION ALONG THE RAY PATH FROM THE AIROLOW EMISSION SHELL FARTHEST FROM THE SATELLITE.

\section{DATA ANALYSIS}

The vertical ozone number density profile determined from the stellar occultation measurements in the $2460 \AA$ channel is determined using the inversion technique discussed by Roble and Hays (1972) and Hays and Roble (1973) and is shown in Fig. 2(b). The dip in the stellar signal near $74 \mathrm{~km}$ is due to a bulge in the ozone number density near $82 \mathrm{~km}$ as discussed previously by Hays and Roble (1973). 
Before the stellar intensity data in the $2980 \AA$ channel can be inverted to obtain the ozone number density distribution, the intensity contribution due to the $2972 \AA$ airglow emission must be removed. To accomplish this we assume that the $2972 \AA$ volume emission rate profile is similar to the volume emission rate of the $5577 \AA$ emission measured by Offermann and Dreshcer (1973) but reduced by the ratio of the respective Einstein radiative transition coefficients. The normalized volume emission rate distribution is shown in Fig. 3(a). The tangential column emission rate as seen by the satellite is determined by integrating the 2972 A volume emission rate along the path length from the star to the satellite assuming that the airglow exists in a spherically symmetric shell. The emission from the airglow layer nearest the satellite is directly received by the satelitite. The emission from the airglow layer beyond the tangent ray point is absorbed by ozone along the ray path under the spherical shell. This absorption can be calculated because the ozone absorption cross-section at $2972 \AA$ is known and the ozone vertical distribution has been determined from the stellar occultation measurements from the $2460 \AA$ channel. The normalized tangential emission rate calculated using the 2972 A volume emission rate profile shown in Fig. 3(a) is shown in Fig. 3(b). The figure shows the calculated emission rate with and without the intervening ozone absorption from the airglow layer farthest from the satellite. The ozone absorption primarily influences the tangential column number density below $60 \mathrm{~km}$.

The peak signal in the 2980 A channel shown in Fig. 1(a) occurs near $90 \mathrm{~km}$ where there is a normalized signal of 1.02. Assuming that 0.02 units are due to the $2972 \AA$ emission, its effect is subtracted from the vertical height profile using the shape of the normalized tangential $2972 \AA$ emission rate profile shown in Fig. 3(b). Once the airglow signal is removed, the $2980 \AA$ channel is inverted in the same manner as used in reducing the $2460 \AA$ data given by Roble and Hays (1972) and Hays and Roble (1972). The filter transmission function and absorption cross-section of ozone used in the data reduction are shown in Fig. 1 of Hays and Roble (1973). The stellar spectrum of the occulting star was measured above the Earth's atmosphere by the OAO-2 stellar spectrometer. The calculated ozone distribution is shown in Fig. 1(b).

\title{
4. DISCUSSION
}

The ozone number density distribution calculated from two distinct wavelength channels show similar ozone distributions. The ozone number density peak being about $3 \times 10^{8}$ as determined by the $2980 \AA$ channel and $2 \times 10^{\mathrm{s}}$ as determined by the $2460 \AA$ channel. Both channels show a minimum in the $75 \mathrm{~km}$ region; however, the magnitude of the ozone density is difficult to retrieve in this region.

The ratio of the stellar signal intensities, shown in Fig. 1(a), is thus proportional to the ratio effective ozone cross-sections covering the spectral band of the filter. If the attenuation were due to dust in the $80 \mathrm{~km}$ region the signal reduction would be nearly the same for both channels because of the relatively flat scattering cross-section for dust. For example, at $82 \mathrm{~km}$ the normalized intensity in the $2460 \AA$ channel is 0.87 , and if a $\lambda^{-1}$ dependence of the scattering cross-section is used, the calculated normalized intensity for the $2980 \AA$ channel would be approximately 0.89 compared to the observed value of 0.97 . Even if the dust scattering cross-section had a $\lambda=4$ dependence, the normalized intensity for the $2980 \AA$ channel would be 0.93 . Thus, it is unlikely that dust is a major factor in the extinction observed near $80 \mathrm{~km}$ at low latitudes.

\author{
National Center for Atmospheric Research,* \\ Boulder, Colorado 80303, U.S.A.
}

R. G. ROBLE

P. B. HAYS

\section{Department of Atmospheric and Oceanic Sciences, University of Michigan, \\ Ann Arbor, Michigan 48105, U.S.A.}

\section{REFERENCES}

Donahue, T. M., GuEnther, B. and Thomas, R. J. (1973). Distribution of atomic oxygen in the upper atmosphere deduced from OGO-6 airglow observations. J. geophys. Res. 28, 6662.

HAYs, P. B. and ROBLE, R. G. (1973). Observation of mesospheric ozone at low latitudes. Planet. Space Sci. 21, 273.

Offremann, D. and Drescher, A. (1973). Atomic oxygen densities in the lower thermosphere as derived from in situ 5577-A night airglow and mass spectrometer measurements. J. geophys. Res. 28, 6690.

RoBL., R. G. and HAYS, P. B. (1972). A technique for recovering the vertical number density profile of atmospheric gases from planetary occultation data. Planet. Space Sci. 20, 1727.

ROBLE, R. G. and HAYS, P. B. (1973). The nighttime distribution of ozone in the low latitude mesosphere. PAGEOPH 106, 1281.

RosenBerg, G. V., Semenov, A. I. and Shefov, N. N. (1974). On the influence of the aerosols for satellite measurements at the thermospheric base. Planet. Space Scl. 22, 1035.

* The National Centre for Atmospheric Research is sponsored by the National Science Foundation. 